\title{
An Analysis of Innovative Abilities Cultivation for Graduates and the Countermeasure Research
}

\author{
Peng $\mathrm{LI}^{1, \mathrm{a}}$ \\ ${ }^{1}$ Northeast Dianli University No. 169 Changchun Road Jilin City, China \\ alip056@163.com
}

Keywords: Graduate student, Innovative ability, Innovative ability cultivation.

\begin{abstract}
The innovation ability of graduate students has been one of the key problems of College education. This paper analyzes the problem of graduate students innovation ability present situation and existence, from the construction of innovation bases, cultivating innovative consciousness, improving the curriculum system, six aspects of strict examination mechanism and put forward some countermeasures to improve the innovation ability of graduate students. Point out the way improving the innovation ability of graduate students.
\end{abstract}

\section{Introduction}

Innovation is an inexhaustible motive force for national survival and development, China is weak in independent innovation capacity, whose integrated innovation level is not high among developing countries; how to improve the capability of independent innovation is one of the key problems restricting China's future development, and the focus on improving the national innovation ability is to improve the ability of the graduate's innovative research [1]. Graduate students will be the mainstay of future construction of an innovative country, and the graduate students innovation ability in our country is obviously insufficient, compared with the developed countries have a larger gap, therefore, to speed up the training of system reform of graduate students in China, focusing on improving the innovation ability of graduate, find a reforming way to improve graduate innovative level is of great significance

\section{Current situation of graduate innovative abilities}

\section{Lack of spirit and sense of innovation}

The spirit and sense of innovation is not only the driving force of innovation activities, but also the basis of the formation of innovation ability of graduate students. Current graduate education focuses on learning basic theory, paying attention to the understanding and knowledge absorption, but often neglects the development and innovation on the basis of this. More and more graduate students lack the spirit of doubt in the learning process, believing firmly on the books of knowledge, which limits the cultivation and set-up of the spirit and sense of innovation.

\section{Low participation rate in innovation activities}

Innovation is the process of turning innovation consciousness into innovation achievements, which is also a process of patience and persistence [2]. At present, it is a common phenomenon that students focus on job oriented study and they can seldom be fully engaged in scientific research innovation activities. The low participation rate in innovation activities has directly affected the transformation of innovation achievements.

\section{The transformation rate of innovation achievements is low}

Innovation achievements is the embodiment of innovation. At present, most research achievements of students is on the basis of previous theories, easy transplantation, simple reasoning and simple extension, only paying attention to reveal the surface phenomenon, not knowing what has caused this phenomenon. Impetuous atmosphere has added to the eagerness of quick success of the students, which make it 
impossible for them to be fully engaged in innovation research. That they are eager to be successful and excellent leads to the low transformation rate and low quality of innovation achievements.

\section{Innovation practice base construction is not perfect}

Innovation ability is not only reflected in the software upgrade, the more important thing is the construction and improvement of the hardware. Nowadays, colleges and universities rarely have the complete construction of innovation practice base for graduate students innovation activities, if any, there are old equipment, infrastructure is not perfect, many problems such as management is not in place, which makes innovation platform inaccessible for graduates and in turn adds to the difficulty of innovation achievements transformation .

In summary, factors that restrict the development of graduate students innovation ability is extremely complex, the interaction of various factors influences each other and is the cause of the current situation of immature graduate innovation abilities. Various factors must be taken into consideration and a systematic scheme must be put forward to improve the current situation so as to consistently improve the innovation abilities of the students.

\section{Methods to improve graduate students innovation abilities}

\section{Strengthen hardware foundation and promote the construction of innovation platform}

A lot of manpower and material resources are needed for the infrastructure construction to create a good innovative environment to improve the students innovation abilities. To increase the input of funds, further improve the construction of innovation platform, update and improve the equipment as far as possible, keep pace with the scientific frontier and the foreign and domestic advanced technology to create a high level of laboratory, practice base, engineering research base of innovation platform. At the same time, strengthen the cooperation with enterprises and scientific research institutions, and use experimental base and engineering practice of enterprises and research institutions to improve the ability of innovation and practice for graduate students. Vigorously promoting the academic exchanges activity to broaden the vision of graduate, stimulate their enthusiasm for scientific research and innovation, and improve the academic ability and academic level [3].

\section{Create innovative atmosphere and cultivate innovative consciousness}

Lack of awareness of innovation and innovative thinking results from the influence and restriction of innovation environment. Most graduate students do not have a complete and thorough understanding of innovation. To strengthen the construction of innovative culture, create a good academic atmosphere; reduce the influence of harmful effects of the society. And correct the graduate students learning attitude. Creative thinking and innovation consciousness training seminars shall be held regularly, enhancing students understanding of innovation, and instruct graduate students on scientific and innovative methods, and provides theoretical support for innovation.

\section{To improved curriculum system and encourage independent innovation}

To get rid of the conventional teaching concept, focus on cultivating the graduate students innovation consciousness [4]. To set up a curriculum focusing on the training graduate students innovative thinking. the curriculum should be emphasizing innovation, to make reasonable proportions between theoretical study and abilities extension. To improve the current situation of passive study and encourage graduates active research and make a free choice in the direction of research. Graduate Innovation Fund for graduate students shall be set up as a financial support. Gradually expand the quality of training and help graduate students understand their own abilities so as to cultivate their innovative thinking.

\section{Create strict examination system and ensure the quality of the paper}

First, a strict assessment system must be created to supervise the study of the graduates. A solid foundation of knowledge is the prerequisite of innovation. Unqualified students shall be ordered to retake the courses accordingly. They must bear a correct attitude towards this. Those who cheat and speculate should be seriously dealt with; if the circumstances are serious, corresponding penalties shall be levied on. 
Secondly, strengthening the examination on the degree in accordance with the innovation is urgent. The thesis must have a clear insight and unique perspective. Any transplant behavior shall be deemed as invalid and a delay of the defense will be inevitable after assessment. A strict assessment system can stimulate the innovation of the graduate and further improve their innovative abilities.

\section{Strengthen the construction of tutors team and improve the quality of instruction}

Tutor, as the direct manager of graduate students, takes an important part in educational management of the graduates. Tutor of graduate students involves in their learning and lives, research direction, research ideas and research supervisor level will influenced by the character students will imitate. So it should vigorously strengthen the construction of tutor's team, the instruction from the tutor shall be more effective and more reasonable to guarantee the quality. A regular evaluation on the performance of the tutor shall be carried out regularly and corresponding award and punishment shall be applied. Encourage tutors to do scientific research innovation, establish tutor innovation fund, encourage the tutor to discover new field and arouse the enthusiasm of the students and do good to the transformation of innovation achievement.

\section{Strengthen cooperation and promote innovation achievement transformation}

Innovation is not only the existence of should be thinking, what we need is ultimately innovation thought into the innovative achievements, and applied to practice, to improve the productivity. How to reasonably transform innovation achievements has been long influencing China's current independent innovation. Especially in academic circles, more academic achievements only exist in the form of paper, has not really put into practice. This requires strengthening mechanism and the cooperation among enterprises, scientific institutes and Colleges and universities, [5]. College is a cradle of innovation thinking, rationality and feasibility analysis is the advantage of scientific research institutions. Enterprises can provide opportunities for innovation practice and testing results, the three complement one another, linked together, forming the innovation achievements transformation system and therefore improve the transformation rate of innovation greatly.

\section{Summary}

Building an innovation oriented country and improve the ability of independent innovation has been one of the major concerns during China's reform and development. With the deepening of reform, we have a deep understanding of the stack only rely on consumption of resources and manpower is not supporting the long-term development of China, we must master the core technology of our own, and all these have to rely on our continuous innovation [6]. As the main power in technology development and progress, graduates in our country are shouldering more responsibilities. Only the concept of innovation and innovative thinking is rooted in the graduate student mind, cultivate their innovative consciousness and innovative ability, encourage its stand on solid ground to participate in scientific research, continuously enterprising, contribute to the magnificent goal of building an innovative country.

\section{References}

[1] Bai Fuchen.Graduates cultivation and contermeasures in China [J].Reform on Talents Cultivation. 2013. (09).

[2] Li Qiaoling, Li Jihong.CultivationMechanism Reform and Development Research on Innovative Abilities of Graduates [J]. Modern Education. 2013(11).

[3] Zhao Xin.Preliminary Stage on Cultivation of Graduate Innovation [J]. Innovation System Constrcution. 2013 (12).

[4] Wang Zhenxu, Gao Yanhua, Zhao Chunsen. A Research on Full -Time Graduate Cultivation with the Carrier of Innovative Practice Base [J]. Seminar.2011(1). 
[5] Zang Xingbing,Lai Xiaoying.A Discovery on the Access to Cultivation of Graduate Innovative Ability [J]. China Higher Education Research.2007(03).

[6] Yi Xiaoming. Main Factors for the Formation of Graduate Innovation Ability [J]. Qilu Journal. 2007(01). 